\title{
Learning paradox: Antecedents and mechanisms of paradox mindset development
}

\section{Introduction}

Organizations face multiple conflicting requirements such as exploration versus exploitation (March, 1991), profit versus social responsibility (Margolis \& Walsh, 2003) or collaboration versus control (Sundaramurthy \& Lewis, 2003). As complexity, global competition and fast-paced technological cycles gain prevalence, these tensions are becoming increasingly salient (Lewis, 2000). Following the insight that "leaders" responses to these tensions may be a fundamental determinant of an organization`s fate", paradox theory has developed a rich description of such tensions (Smith \& Lewis, 2011, p. 381), which are characterized by "persistent contradictions between interdependent elements" (Schad et al., 2016, p.6). The ability of individual employees (e.g. Gibson \& Birkinshaw, 2004), managers (e.g. Mom, van den Bosch \& Volberda, 2009) and executives (e.g. Smith \& Tushman, 2005) to manage such paradoxical demands is an important micro-foundation of the organizational capability to do so. Still, research on the individual level remains scarce (Schad et al., 2016). Recent paradox research found enduring differences in individuals proclivity and ability to manage paradoxes (MironSpektor et al., 2018). This antecedent of paradoxical cognition was framed as paradox mindset and the authors provided evidence for its moderating role for paradoxical tensions' performance effects (Miron-Spektor et al., 2018).

Paradox mindset is thus an important antecedent for paradoxical cognition and the management of paradoxical tensions. However, we know little about the antecedents or evolution of paradox mindset itself: Can it be developed and if so, how? "If paradoxical thinking can be taught, we need to clarify what might be some of the best ways to do so" (Schad et al., 2016, p. 41). Accordingly, we build in this study on psychological mindset theory (Dweck, 2006) and argue that paradox mindset can indeed be developed through informational (e.g. Blackwell, Trzesniewski \& Dweck, 2007) and motivational (e.g. Muller \& Dweck, 1998) approaches. Informational approaches refer to changes in someone's basic convictions about the world. These may be developed, for example, through role modelling of a paradoxical leader on higher levels in the organizations. Motivational approaches, on the other hand, refer to shaping mindset through feedback and reward processes, which are again executed by the leaders in an organization. Accordingly, we propose that paradoxical leadership is a particularly suitable candidate to develop paradox mindset since it works through both approaches (cf. Anderson, Boaler \& Dieckmann, 2018).

We draw on primary data from 199 employees from two Central European companies to empirically test our hypotheses: We find strong empirical support for our prediction that paradoxical leadership leads to paradox mindset. However, this effect is fully mediated by the individuals' experiences with engaging in paradoxical tasks (i.e., individual ambidextrous behavior). This suggest that paradoxical management, paradoxical behavior, and paradox mindset are inherently linked to one another in a recursive, self-reinforcing feedback loop. Our results have important implications both for theory and practice. For theory, we identify to our knowledge the first antecedents of paradox mindset and their respective mechanisms. In addition, we contribute to emerging paradox research focused on a process perspective and learning feedbacks between paradoxical management and paradoxical capabilities. For practice, we identify practical ways how leaders may increase the paradoxical capabilities of their followers.

\section{Theory}

Mindset Theory is based on the observation that individuals have to use simplifying mental processes to make sense of a world filled with complex, ambiguous and contradictory information (Taylor \& Crocker, 1981). A mindset is defined as a "mental frame or lens that selectively organizes and encodes information, thereby orienting an individual toward a unique way of understanding an experience and guiding one towards corresponding actions and responses" (Crum et al., 2013). Such mindsets have been demonstrated to be highly consequential for dealing with ambiguous or ambivalent stimuli in psychological research. For example, mindsets about aging determine not only physiological reactions (Levy, Hausdorff, Hencke \& Wei, 2000) but also longevity (Levy et al., 2002), and mindsets about intelligence determine educational outcomes (Blackwell et al., 2007). Mindset theory has recently been linked to paradoxical thinking (Miron-Spektor et al., 2018). Paradox mindset is conceptualized as a general proclivity for accepting, valuing and proactively integrating paradoxical tensions irrespective of the particular tension type (cf. Miron-Spektor et al., 2018). Past research has shown paradox mindset 
to shape the way people perceive and make sense of paradoxical tensions. Instead of perceiving these tensions as dilemmas, a paradox mindset "shifts expectations from rationality and linearity to accepting paradoxes as persistent and unsolvable puzzles" (Smith \& Lewis, 2011, p. 385). Furthermore, paradox mindset was shown to moderate the effects of paradoxical tensions such as exploration and exploitation on performance: While high paradoxical tensions were found to have a positive impact on the performance of employees with a high paradox mindset, they appeared to have a negative effect for those with a low paradox mindset (Miron-Spektor et al., 2018).

Given these important insights on the characteristics and effects of paradox mindset, we know surprisingly little about their antecedents and evolution. We therefore build on a second tenant from mindset theory, i.e. the fact that mindsets can be learned and developed. In psychological research, there is ample evidence for the possibility to change mindsets (Aronson et al., 2002; Chiu, Hong \& Dweck, 1997; Crum \& Langer, 2007; Crum et al., 2013; Dweck, 2008). For example, Crum and Langer (2007) successfully manipulated housecleaners' mindsets about the nature of their work. This led to significant reductions in their Body-Mass-Index and systolic blood pressure. In general, approaches to change or develop mindsets can be categorized in two separate but complementary intervention angles: informational and motivational approaches.

Informational approaches to changing mindsets target one of the building blocks of mindsets, i.e. the basic convictions or lay theories (Chiu et al., 1997) about the world: Is intelligence fixed at birth or something that is developed with practice (Dweck, 2008)? Is stress good or bad for you (Crum et al., 2013)? In the context of our study, such a conviction may also relate to whether an individual perceives paradoxes as both contradictory and interdependent tensions which can be worked through in both / and solutions, or if they are perceived as trade-offs that preclude each other (Miron-Spektor et al., 2018). These lay theories are explicit, descriptive and ontological assumptions about the world and can be updated by providing new information about the world in a persuasive way: For example, Blackwell and colleagues (2007) changed mindset about intelligence in an 8-week course, which explained mechanisms of neural plasticity, whereas Chiu and colleagues (1997) appealed through authority by presenting students with a "scientific article" which argued compellingly for either a fixed or malleable view of intelligence in order to change mindsets. A central role for developing a paradox mindset through such informational approaches may reside in the leadership on higher levels in the organization. Paradoxical leadership is a multi-dimensional construct, which describes leadership behaviors which meet paradoxical demands in different kinds of paradoxical tensions. Rather than providing information in the sense of a scientific statement (Chiu et al., 1997) or by explaining logical mechanisms (Blackwell et al., 2007), paradoxical leaders may thus provide a concrete and personal example that it is possible to integrate paradoxical tensions. Such personal experiences, especially when coming from an authority figure such as a leader, can be even more persuasive than scientific statements (e.g. De Wit, Das \& Vet, 2008), which are often used in the informational approach to changing mindsets (Chiu et al., 1997).

Complementarily, motivational approaches to changing mindsets refer to the self-referential dynamic in mindsets which can be described as hot cognition (Brand, 1985), i.e. cognition that is shaped and influenced by emotional and motivational dynamics: Mindsets about intelligence, for example, are not merely abstract, scientific observations about the world, but have very real consequences for the self-attribution of individuals. Accordingly, approaches to changing mindsets have also focused on such motivational factors. For example, Muller and Dweck (1998) demonstrated that feedback can be used to change mindsets, whereas O`Rourke and colleagues (2014) changed reward structures in an online learning environment to develop mindsets. We propose that paradoxical leadership may also affect paradox mindset through the motivational angle as leaders are a natural source of feedback and rewards in organizations. Moreover, the notion that leadership maybe an important way to develop mindsets in organizations is consistent with the empirical observation that teachers have been shown to develop the mindsets of their students (Anderson et al., 2018). Thus, we hypothesize:

\section{H1: Higher levels of paradoxical leadership increase individuals' paradox mindset.}

We further build on mindset theory and paradox theory to explore the mechanism of how paradoxical leadership leads to increased paradox mindset. Importantly, interventions to changing mindsets are effective because they engender self-reinforcing cycles of change (Yeager \& Walton, 2011). Initially, an intervention to change a mindset primes a corresponding cognitive frame which is temporally held by the individual. This novel cognitive frame in turn shapes the affordances, interpretations, and behavioral tendencies of the environment from 
the individual. The changes in behavior, finally, are stabilized in form of an enduring mindset as they are rewarded and confirmed through the changes in outcomes the individual reaps. For example, in the case of growth mindset, interventions to change growth mindset produced a different cognitive frame in terms of goals and beliefs about the value of effort (Blackwell et al., 2007). This cognitive frame predicts behavioral reaction to setbacks (Blackwell et al., 2007): If and individual beliefs that intelligence can be developed (is fixed), setbacks are a chance to maximize learning (an indicator of lacking talent). Thus, individuals maximize learning (avoid these kinds of situations in the future). As their behavior changes, their new experience fits the new mindset and reinforces it, as they experience that they can indeed learn from failure (are rewarded for sticking to what they already know). A similar, self-reinforcing dynamic has been proposed in the case of stress mindset (Crum et al., 2013).

We propose a similar mechanism of self-reinforcing cycles to explain changes in paradox mindset. Specifically, we suggest that paradoxical leadership primes followers to adopt a paradoxical cognitive frame (Miron-Spektor, Gino \& Argote, 2011). As followers adopt a paradoxical cognitive frame, their propensity for perceiving their environment as paradoxical and engaging in paradoxical tasks increases (Leung, Liou, MironSpektor, Koh \& Chan, 2018; Miron-Spektor \& Beenen, 2015). In line with existing literature on paradoxical management, this in turn triggers self-reinforcing cycles of adaptation (Tsoukas \& Cunha, 2017) or decline (Sundaramurthy \& Lewis, 2003) which reinforce and stabilize the primed paradoxical frame as a mindset: As followers start to engage their environment as characterized by persistent contradictions, they experience the potential in synergies between opposites which rewards their engagement and stabilizes the new perspective into a subjective conviction or mindset. Although our argument about the importance of behavioral changes in explaining changes in paradox mindset is generic, we follow the existing literature on paradoxical cognitive frames, which has mostly focused on the effect of paradoxical cognitive frames on the management of learning tensions (Leung et al., 2018; Miron-Spektor \& Beenen, 2015; Miron-Spektor, Gino \& Argote, 2011). Learning tensions between exploration and exploitation are addressed at the individual level in the form individual ambidexterity (Mom et al., 2009). Thus, we hypothesize

H2: The effect of paradoxical leadership on paradox mindset is mediated through the individuals' level of engagement in paradoxical tasks (i.e., individual ambidextrous behavior).

\section{Methods and Results}

\section{Procedure and sample}

We collected primary data from two companies. Company A is in the service industry, Company B in the manufacturing industry. Both are located in Central Europe with 6.600 employees and an annual turnover in 2017 of 8.64 bn CHF (Company A) and 9.500 employees and an annual turnover in 2017 of 1.63 bn CHF (Company B). Cooperation was secured after explaining the purpose of the study to the director of HR (Company A) and the CEO (Company B), respectively. After ensuring the employees of the confidential treatment of their data, the link to the survey was sent to a random subsample of each company's employees. After excluding employees with incomplete survey data, a total of 199 responses were included in the analysis (108 from Company A with a response rate of $53 \%$ and 91 from Company B with a response rate of $86 \%$ ). The sample included participants from different work areas (13\% worked in research \& development, $25 \%$ in services and production, $20 \%$ in sales and marketing, $10 \%$ in logistic and support, $8 \%$ in internal services, $4 \%$ in controlling, $2 \%$ in procurement, $9 \%$ in $\mathrm{HR}, 7 \%$ in IT and $4 \%$ in communications). The average tenure was 13 years (standard deviation 11.3 years).

\section{Measurement}

We measured paradoxical leadership by relying on the five-item scale developed by Zhang and colleagues (2015) with all questions relating to the respondent's experiences in the 12 months prior to the survey. The individuals' level of engagement in paradoxical tasks was operationalized through the individual ambidexterity construct by Mom and colleagues (2009) as the product of individual exploration and exploitation behavior over the 12 months prior to data collection (e.g. Kauppilla \& Tempelaar, 2016). Paradox mindset was measured based on the eponymous scale developed by Miron-Spektor and colleagues (2018). Finally, in line with existing research on paradoxical cognition (Miron-Spektor et al., 2018), we include gender, education and organizational tenure as control variables. In addition, we include a dummy variable for the company as a control 
to rule out the possibility that effects are caused by systematic differences between the two companies in the sample.

\section{Results}

Table 1 presents descriptive statistics and correlations of the study variables. In order to test for hypothesis 1 , we conducted a linear regression of paradox mindset, with results depicted in table 2.

Table 1. Descriptive statistics and correlations of study variables. Significance at $\mathrm{p}<.05, .01, .001$ indicated as $*, * *, * * *$, respectively.

\begin{tabular}{|c|c|c|c|c|c|c|c|c|c|c|}
\hline \multicolumn{2}{|c|}{ Variable } & Mean & S.D. & (1) & (2) & (3) & (4) & (5) & (6) & (7) \\
\hline (1) & $\begin{array}{l}\text { Paradoxical } \\
\text { Leadership }\end{array}$ & 3.82 & 0.86 & & $.17^{*}$ & $.21 * *$ & -.11 & .09 & -.02 & -.03 \\
\hline (2) & $\begin{array}{l}\text { Paradoxical } \\
\text { Mindset }\end{array}$ & 3.31 & 0.69 & $.17 *$ & & $.38 * *$ & -.01 & $.22 * *$ & $.17 *$ & -.13 \\
\hline (3) & $\begin{array}{l}\text { Engagement in } \\
\text { paradoxical task }\end{array}$ & 12.47 & 3.62 & $.21^{* *}$ & $.38 * *$ & & .04 & .08 & .01 & -.01 \\
\hline (4) & Tenure & 13.06 & 11.28 & -.11 & -.01 & .04 & & $-.27 * *$ & .09 & $-.25 * *$ \\
\hline (5) & Education & 2.52 & 1.09 & .09 & $.22 * *$ & .08 & $-.27 * *$ & & $.18 * *$ & $-.15^{*}$ \\
\hline (6) & Gender & 1.70 & 0.49 & -.02 & $.17 *$ & .01 & .09 & $.18^{* *}$ & & $-.42 * *$ \\
\hline (7) & Company & 0.54 & 0.50 & -.03 & -.13 & -.01 & $-.25 * *$ & $-.15^{*}$ & $.42 * *$ & \\
\hline
\end{tabular}

Table 2: Regression Model of Paradox Mindset

\begin{tabular}{|lllll|}
\hline & \multicolumn{4}{l}{ Paradox Mindset } \\
\cline { 2 - 5 } Variable & Coefficient & S.D. & t-value & $p$-value \\
\hline Intercept & $2.22^{*} * *$ & 0.34 & 6.43 & $<.001$ \\
Paradoxical Leadership & $0.13^{*}$ & 0.06 & 2.35 & .02 \\
Gender & 0.17 & 0.11 & 1.62 & .11 \\
Education & $0.12 *$ & 0.05 & 2.60 & .01 \\
Tenure & 0.01 & 0.01 & 0.55 & .59 \\
Company & -0.05 & 0.11 & -0.45 & .65 \\
\hline
\end{tabular}

In order to test for hypothesis 2, we used the process macro in SPSS for testing our mediation model. Path coefficients are depicted in figure 1 , bootstrapping indicates a significant indirect effect $(\mathrm{b}=.06, \mathrm{BootSE}=$ $.02[.02, .11])$.

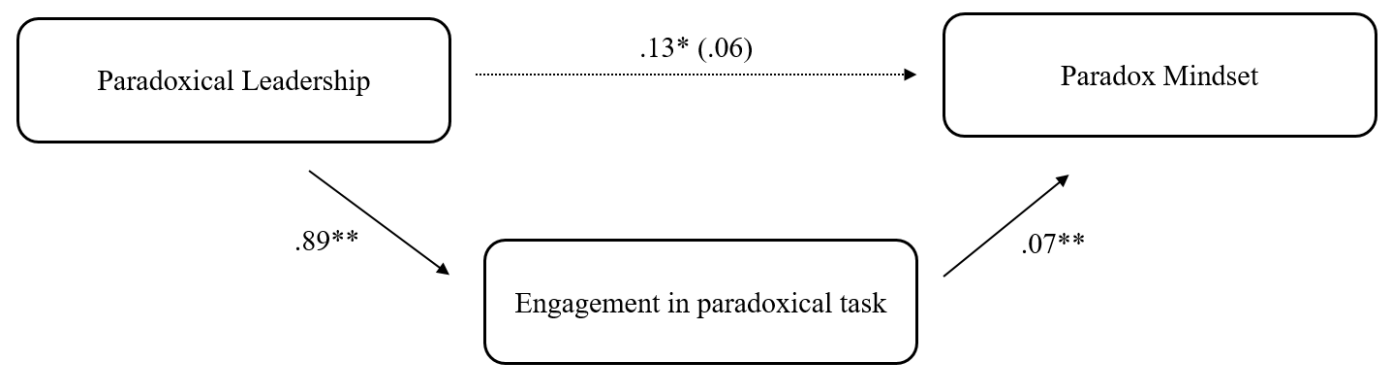

Figure 1: Mediation model with total, direct and indirect effect as indicated by unstandardized regression coefficients. The same control variables are included as in the regression model for hypothesis 1 .

\section{Discussion}

Building on psychological mindset theory, our study identifies paradoxical leadership as a key antecedent to develop paradox mindset. Furthermore, we build on paradox theory and argue that this positive effect is mediated through a virtuous cycle engendered by individuals' engagement in paradoxical tasks. Building on 
primary data from 199 employees, we find strong empirical support for our predictions: Paradoxical leadership in the past 12 months leads to increased paradox mindset, and this effect is fully mediated through more paradoxical activities. These insights have important implications for both for theory and practice.

For theory, we present the first results suggesting that paradox mindset is a malleable characteristic which can be shaped and developed. Paradox mindset has recently received research attention (Keller, Loewenstein \& Yan, 2017; Miron-Spektor et al., 2018) given its central role in explaining interindividual variability in the management of paradoxical tensions. In line with a micro-foundation perspective (Felin, Foss \& Ployhart, 2015) and paradox theory (Smith \& Tushman, 2005), individual managerial ability to manage paradoxical tensions can be considered a crucial basis for the organizational ability to thrive in a paradoxical world (cf. Lewis, 2000; Smith \& Lewis, 2011). We identify paradoxical leadership as an actionable angle to develop such paradox mindset in a viable way in the organizational setting. Furthermore, we theoretically derive two central pathways how paradox mindset can be developed, thus providing guidance for future research to dive deeper into practical ways of how paradox mindset can be shaped. Second, we contribute novel insights to emerging research taking a more processoriented perspective on paradox and paradox management (Schad et al., 2016). Extant literature mostly used paradoxical capabilities such as paradoxical cognition or paradox mindset as antecedents to explain management of paradoxical tensions (Keller et al., 2017; Miron-Spektor et al., 2018; Smith \& Tushman, 2005). In contrast, our study demonstrates that engaging in paradoxical tasks may in turn also lead to the building of paradoxical capabilities. These insights are well aligned with recent conceptual ideas regarding learning spirals that explain the development of paradoxical capabilities (Raisch, Hargrave \& Van de Ven, 2018). Uncovering the supporting role of paradoxical activities for the development of paradoxical capabilities allows us to close these proposed feedback loops.

For practitioners, our study is the first to point towards actionable angles how the individual ability to manage paradoxical tensions can be developed through leadership. In addition, we demonstrate that the investment in paradoxical management strategies not only offers benefits in itself, but also contributes to the subsequent building of paradoxical capability in the form of paradox mindset.

As all empirical research, our study is not without limitations. With regards to the sampling, we only included employees from two companies. While we controlled for that, the relationships we observed could be influenced by specific contextual factors in the companies included in our sample. Although we theoretically identify two angles how paradoxical leadership might influence paradox mindset, we didn`t explicitly measure these processes in our data. Finally, while respondents rated the predictor variables anchored on the last 12 months, all data was measured at a single point in time. While we consider the theoretical rational for the direction of causality in our model to be convincing, this still introduces the possibility of reverse causality. Future research should address these shortcomings with a truly longitudinal research design, thereby not only controlling for common method variance, but also introducing a stronger claim of causality. Sampling more than two companies and explicitly measuring process variables such as motivational and informational influence of paradoxical leadership would lend further credibility to the proposed relationship. Finally, a multilevel design could analyze how the development of paradoxical mindset affects organizational level management approaches for paradoxes.

With our research, we hope to provide a first step towards a more in-depth understanding of the learning dynamics between paradox capability and paradox mindset and we hope that our findings will be instructive for further research diving deeper into this fascinating novel ground. 


\section{References}

Anderson, R., Boaler, J., \& Dieckmann, J. (2018). Achieving elusive teacher change through challenging myths about learning: A blended approach. Education Sciences, 8(3), 98.

Aronson, J., Fried, C. \& Good, C. (2002). Reducing the effect of stereotype threat on African American college students by shaping theories of intelligence. Journal of Experimental Social Psychology, 38, 113-125.

Blackwell, L. S., Trzesniewski, K. H., \& Dweck, C. S. (2007). Implicit theories of intelligence predict achievement across an adolescent transition: A longitudinal study and an intervention. Child Development, 78(1), 246-263.

Brand, A. G. (1985). Hot cognition: Emotions and writing behavior. Journal of Advanced Composition, 5-15.

Chiu, C. Y., Hong, Y. Y., \& Dweck, C. S. (1997). Lay dispositionism and implicit theories of personality. Journal of Personality and Social Psychology, 73(1), 19.

Crum, A. J., \& Langer, E. J. (2007). Mind-set matters: Exercise and the placebo effect. Psychological Science, 18(2), 165-171.

Crum, A. J., Salovey, P., \& Achor, S. (2013). Rethinking stress: The role of mindsets in determining the stress response. Journal of Personality and Social Psychology, 104(4), 716.

De Wit, J. B., Das, E., \& Vet, R. (2008). What works best: objective statistics or a personal testimonial? An assessment of the persuasive effects of different types of message evidence on risk perception. Health Psychology, 27(1), 110.

Dweck, C.S. (2006). Mindset. New York, NY: Random House.

Dweck, C. S. (2008). Mindset: The new psychology of success. Random House Digital, Inc..

Gibson, C. B., \& Birkinshaw, J. (2004). The antecedents, consequences, and mediating role of organizational ambidexterity. Academy of Management Journal, 47(2), 209-226.

Kauppila, O. P., \& Tempelaar, M. P. (2016). The social-cognitive underpinnings of employees' ambidextrous behaviour and the supportive role of group managers' leadership. Journal of Management Studies, 53(6), 10191044.

Keller, J., Loewenstein, J., \& Yan, J. (2017). Culture, conditions and paradoxical frames. Organization Studies, 38(3-4), 539-560.

Leung, A. K. Y., Liou, S., Miron-Spektor, E., Koh, B., Chan, D., Eisenberg, R., \& Schneider, I. (2018). Middle ground approach to paradox: Within-and between-culture examination of the creative benefits of paradoxical frames. Journal of Personality and Social Psychology, 114(3), 443.

Levy, B. R., Hausdorff, J. M., Hencke, R., \& Wei, J. Y. (2000). Reducing cardiovascular stress with positive self-stereotypes of aging. The Journals of Gerontology Series B: Psychological Sciences and Social Sciences, 55(4), P205-P213.

Levy, B.R., Slade, M.D., Kunkel, S.R. \& Kasl, S.V. (2002). Longevity increased by positive self-perceptions about aging. Journal of Personality and Social Psychology, 83,261-270.

Lewis, M. W. (2000). Exploring paradox: Toward a more comprehensive guide. Academy of Management Review, 25(4), 760-776.

March, J. G. (1991). Exploration and exploitation in organizational learning. Organization Science, 2(1), 71-87.

Margolis, J. D., \& Walsh, J. P. (2003). Misery loves companies: Rethinking social initiatives by business. Administrative Science Quarterly, 48(2), 268-305.

Miron-Spektor, E., \& Beenen, G. (2015). Motivating creativity: The effects of sequential and simultaneous learning and performance achievement goals on product novelty and usefulness. Organizational Behavior and Human Decision Processes, 127, 53-65. 
Miron-Spektor, E., Gino, F., \& Argote, L. (2011). Paradoxical frames and creative sparks: Enhancing individual creativity through conflict and integration. Organizational Behavior and Human Decision Processes, 116(2), 229-240.

Miron-Spektor, E., Ingram, A., Keller, J., Smith, W. K., \& Lewis, M. W. (2018). Microfoundations of organizational paradox: The problem is how we think about the problem. Academy of Management Journal, 61(1), 26-45.

Mom, T. J., Van Den Bosch, F. A., \& Volberda, H. W. (2009). Understanding variation in managers' ambidexterity: Investigating direct and interaction effects of formal structural and personal coordination mechanisms. Organization Science, 20(4), 812-828.

Muller, C., \& Dweck, C.S. (1998). Praise for intelligence can undermine children's motivation and performance. Journal of Personality and Social Psychology, 75(1), 33-52.

O'Rourke, E., Haimovitz, K., Ballweber, C., Dweck, C., \& Popović, Z. (2014, April). Brain points: a growth mindset incentive structure boosts persistence in an educational game. In Proceedings of the SIGCHI conference on human factors in computing systems (pp. 3339-3348). ACM.

Raisch, S., Hargrave, T. J., \& Van De Ven, A. H. (2018). The learning spiral: A process perspective on paradox. Journal of Management Studies, 55(8), 1507-1526.

Schad, J., Lewis, M. W., Raisch, S., \& Smith, W. K. (2016). Paradox research in management science: Looking back to move forward. The Academy of Management Annals, 10(1), 5-64.

Sundaramurthy, C., \& Lewis, M. (2003). Control and collaboration: Paradoxes of governance. Academy of Management Review, 28(3), 397-415.

Smith, W. K., \& Lewis, M. W. (2011). Toward a theory of paradox: A dynamic equilibrium model of organizing. Academy of Management Review, 36(2), 381-403.

Smith, W. K., \& Tushman, M. L. (2005). Managing strategic contradictions: A top management model for managing innovation streams. Organization Science, 16(5), 522-536.

Taylor, S.E. \& Crocker, J. (1981). Schematic bases of social information processing. In T.E. Higgins \& P.C. Herman (Eds.). Social cognition (pp.89-134). Hillsdale, NJ: Erlbaum.

Tsoukas, H., \& Cunha, M. P. (2017). On Organizational Circularity. The Oxford Handbook of Organizational Paradox, 393.

Yeager, D. S., \& Walton, G. M. (2011). Social-psychological interventions in education: They're not magic. Review of Educational Research, 81(2), 267-301.

Zhang, Y., Waldman, D. A., Han, Y. L., \& Li, X. B. (2015). Paradoxical leader behaviors in people management: Antecedents and consequences. Academy of Management Journal, 58(2), 538-566. 